\title{
Urbanicity is Associated with Behavioral and Emotional Problems in Elementary School-Aged Children
}

\author{
Brittany E. Evans $\mathbb{D}^{1,2,3} \cdot$ J. Marieke Buil ${ }^{2,4} \cdot$ William J. Burk ${ }^{1}$ Antonius H. N. Cillessen ${ }^{1}$ - Pol A. C. van Lier ${ }^{2,4}$
}

Published online: 29 March 2018

(c) Springer Science+Business Media, LLC, part of Springer Nature 2018

\begin{abstract}
Adults are $38 \%$ more likely to suffer from a psychiatric disorder when they live in an urban compared to a rural area. Urban upbringing may be particularly important. The aim of the present study was to examine whether urbanicity was independently associated with mental health in elementary school-aged children. Specifically, we investigated whether living in a more urban area was associated with exhibiting more behavioral and emotional problems, and whether this remained while controlling for other major risk factors for mental health problems in children. Data came from a Dutch general population study of children $(n=895)$. Information from four waves was used, in which children were aged approximately $8,9,11$, and 12 years old. We used mixed effects models to assess the association between urbanicity and the outcomes of behavioral problems and emotional problems separately, while controlling for other major risk factors. The analyses showed that children who lived in more urban areas were significantly more likely to exhibit behavioral $(p<.001)$ and emotional $(p$ $<.001)$ problems. This effect remained when controlling for neighborhood socioeconomic status, gender, ethnicity, family socioeconomic status, parental symptoms of psychopathology, parenting stress, and parenting practices (behavioral: $p=.02$, emotional: $p=.009$ ). In line with research in adults, urbanicity seems to be independently associated with behavioral and emotional problems in children. A possible underlying mechanism is that the city is a stressful environment for children to grow up in, which contributes to an increased risk for mental health problems.
\end{abstract}

Keywords Urbanicity $\cdot$ Children $\cdot$ Mental health $\cdot$ Behavioral problems $\cdot$ Emotional problems

\section{Introduction}

Urbanization is steadily increasing worldwide: today, more than half of the world's population lives in a city (United Nations 2014). Although health in general is better in urban areas (Dye 2008), living in a city has adverse effects on peoples' mental health (Cyril et al. 2013). Depression, anxiety disorders, autism, substance abuse, schizophrenia,

Electronic supplementary material The online version of this article (https://doi.org/10.1007/s10826-018-1062-z) contains supplementary material, which is available to authorized users.

\footnotetext{
$\triangle$ Brittany E. Evans

brittany.evans@kau.se

1 Radboud University, Nijmegen, The Netherlands

2 VU University Amsterdam, Amsterdam, The Netherlands

3 Karlstad University, Karlstad, Sweden

4 Erasmus University Rotterdam, Rotterdam, The Netherlands
}

and behavioral problems are significantly more prevalent in urban residents than in those living in more rural areas (e.g., Peen et al. 2010). The current view holds that a greater demand for social stress processing in cities may explain this (Mizrahi 2016; van Os et al. 2010). For example, people living in cities may be more likely to be confronted with social stressors such as social evaluative threat, social defeat and chronic social stress (Lederbogen et al. 2011). Evidence suggests that the association between urbanicity and mental health is not the consequence of indirect processes, such as selective migration, but that urban-living constitutes an independent risk factor for mental health problems (Krabbendam and van Os 2005). Retrospective studies suggest that having grown up in a city increases this risk (Marcelis et al. 1998).

Only a few studies have considered associations between urbanicity and developmental outcomes in children. Rutter and colleagues reported a higher prevalence of psychiatric disorders in children living in inner-city London compared to those living in rural towns on the Isle of Wight (Rutter 1981; Rutter et al. 1975). In this seminal study, it was found that 
rates of both conduct disorders (e.g., aggression, delinquency) and emotional disorders (e.g., fears, worry, unhappiness) were higher in residents of urban compared to rural areas (Rutter et al. 1975; Rutter 1981). Since then, a few large-scale studies utilizing national registry data confirmed this association. Autism spectrum disorder was reported to be more prevalent in children living in urban areas compared to rural areas (Lauritsen et al. 2014; Williams et al. 2006). Similarly, children in Taiwan were more likely to receive a diagnosis of autism and attention deficit disorder when they were living in urban areas compared to rural areas (Chen et al. 2007; Lai et al. 2012). A recent study showed that British children from urban areas reported more psychotic symptoms than those from rural areas (Newbury et al. 2016). Thus, children who live in more urban areas may be especially at risk for developing (symptoms of) mental health problems. The previous research in children and adults suggests that the association is not specific to certain psychiatric disorders, rather, that it pertains to a broad range of problems, both behavioral and emotional in nature.

Of course, there are many potential risk factors for mental health problems in children, and urbanicity is only one of these. Most previous studies on urbanicity and mental health in children did not have detailed information at the individual and family level (e.g., family socioeconomic status, parental mental health). Yet, arguably the strongest predictors of mental health problems in children may be individual/family factors, for example, gender. Findings are consistent in that boys seem to show more behavioral problems, and girls seem to show more emotional problems, although this difference does not emerge until (pre-)puberty (Bongers et al. 2003). Differences in ethnicity have also been documented: youth from non-western minorities tended to report more mental health problems (Reijneveld et al. 2005). Parental factors have been shown to be an important influence on behavioral and emotional problems in children, most prominently parental (symptoms of) psychopathology (Beardslee et al. 1998; Amrock and Weitzman 2014). Parenting stress has been fairly robustly related to mental health problems (Ashford et al. 2008; Bayer et al. 2008), with recent evidence suggesting bidirectional effects (Stone et al. 2016). Parenting practices characterized by, for example, low support, poor monitoring and harshness, are another frequently-investigated parental factor. Such parenting practices have been associated with a higher prevalence of both behavioral (Rothbaum and Weisz 1994) and emotional (Rapee 2012) problems in children.

Low socioeconomic status is one of the most welldocumented environmental risk factors for mental health problems in children, whether measured at the family or neighborhood level (e.g., Duncan et al. 2016; Leventhal and Brooks-Gunn 2003; Sellstrom and Bremberg 2006). Some studies suggested that family-level socioeconomic status mediates the relation between neighborhood-level socioeconomic status and mental health problems (Reijneveld et al. 2010), although others reported that neighborhood-level effects may be more influential (Kalff et al. 2001; Sellstrom and Bremberg 2006). There is a substantial amount of research concerned with the effects of the neighborhood on youth, underscoring how dangerous and disadvantaged neighborhoods can be detrimental for the development and functioning of youth (Caspi et al. 2000; Leventhal and Brooks-Gunn 2000). These studies controlled for important individual and family factors, and provided evidence for specific aspects of the neighborhood that could be most influential (e.g., lack of social cohesion; Sampson et al. 1997) as well as family-level mediators (e.g., parenting practices; Odgers et al. 2012). In our study, we controlled for neighborhood-level socioeconomic status.

In the current study, we examined whether urbanicity was a neighborhood-level risk factor for mental health problems in youth, independent of socioeconomic status. Most previous studies examining the urbanicity-mental health association focused on psychiatric disorders (i.e., whether individuals met diagnostic criteria for specific disorders such as schizophrenia or depression). In our study we were interested in mental health problems in a broader sense, therefore we examined children's behavioral and emotional problems as our outcome measure. These may include symptoms of psychiatric disorders, however children may not exhibit enough symptoms to warrant a diagnosis. In this way, subclinical behavioral and emotional problems are less severe, although they affect a larger portion of the population than clinical disorders do. Moreover, studies showed that children who exhibited subclinical behavioral and emotional problems reported significant impairment in their daily lives due to these problems (Ravens-Sieberer et al. 2008) and were more likely to be diagnosed with a clinical psychiatric disorder in adulthood (Dingle et al. 2010).

Previous research on the association between mental health and urbanicity primarily entailed large-scale studies conducted at the national level. Such studies have been essential in establishing a posited link between urbanicity and mental health, however, detailed information at the individual/family level was often lacking. At this point, very little is known about whether urbanicity is associated with mental health while controlling for other known risk factors for mental health problems. Therefore, in this study, we tested whether urbanicity remained associated with behavioral and emotional problems when controlling for neighborhood (i.e., socioeconomic status), individual (i.e., gender, ethnicity), and family (i.e., socioeconomic status, parental symptoms of psychopathology, parenting stress, parenting practices) characteristics. We hypothesized that urbanicity would remain positively associated with behavioral and emotional problems when controlling for these other risk factors. Urbanicity was indicated by neighborhood-level 
density of surrounding addresses (a measure signifying the degree of human activity a given area).

\section{Method}

\section{Participants}

Participants were children in a larger longitudinal study on the development of social, emotional, and behavioral problems. The study was originally designed to test the effects of an intervention targeting behavior problems (see Witvliet et al. 2009). The current study focused on elementary school children; therefore we used data from the calendar years 2005-2010, when children were approximately 7 through 12 years old. We did not use data from 2008 due to a lack of home address information for that year. The final sample ( $N=895$; see section 'Available data') of the current study was based on available data on teacher-reported behavioral and emotional problems and home address (which was used to extract neighborhood-level information). In this final sample, approximately half were male (49\%), the majority was of Dutch ethnicity (63\%), and 32 percent were from low socioeconomic status families.

\section{Procedure}

The study protocol was approved by the Medical Ethics Committee of the Erasmus University Medical Center (protocol number MEC 199.979/2001/53). The study was conducted via elementary schools that were located in two urban areas in the west of the Netherlands and one rural area in the east of the Netherlands. Recruitment of the schools took place in 2004, and the first 30 schools that agreed to participate were included in the study. Children who were in kindergarten classes at the start of the study, and whose parents gave informed consent, were included in the study. These children were subsequently followed: data were collected annually (in the spring) or biannually (in the spring and autumn) until 2011. For each new data collection wave, parents were informed of the data collection plans and were given the opportunity to revoke the inclusion of their child or themselves in the study. In 2005 and 2006, questionnaire packets were sent home to parents with questionnaires on, for example, parent symptoms of psychopathology and parenting practices.

\section{Measures}

\section{Behavioral and emotional problems}

Behavioral and emotional problems were reported by classroom teachers on the Problem Behavior at School
Interview (Erasmus University Medical Center 2000). This questionnaire was developed to assess symptoms of psychopathology in school-aged children. Teachers completed the questionnaire once or twice during each year of the study in a face-to-face interview with a research assistant. For each child in a classroom, they answered 39 items, rated on a five-point Likert scale, on five subscales indexing how often symptoms of anxiety, depression, attention deficit/ hyperactivity disorder, oppositional defiant disorder, and conduct disorder occurred. A shortened version (30 items) was used in the spring of 2006, the fall of 2007, and in 2009. Due to the focus of the current study on behavioral and emotional problems, we used the mean of the subscales for symptoms of oppositional defiant disorder and conduct disorder as an indication of behavioral problems, and the mean of the subscales for symptoms of anxiety and depression as an indication of emotional problems. We first computed the means for each composite subscale for each year of the study as the questionnaire was completed twice per year in 2006 and 2007, and once per year in 2009 and 2010. We then computed the means of the composite subscales across the 4 years of the study. The reliability statistics of the subscales were acceptable to excellent (mean Cronbach's $\alpha=.85$, range: .73-.92).

\section{Neighborhood characteristics}

Neighborhood characteristics (i.e., urbanicity and socioeconomic status) were measured at the neighborhood level. Neighborhoods are defined by Statistics Netherlands as part of a municipality with a homogenous socioeconomic structure or planning, and have a population of approximately 1400 on average (Statistics Netherlands 2016). We extracted data on the neighborhood of each participant from Statistics Netherlands (Statistics Netherlands 2015) for each year of the study in which they participated.

Urbanicity was a continuous measure defined as the degree of human activity in a given area, with a higher score indicating a more urban area. It was based on the number of addresses within a circle of 1-kilometer radius around an address (surrounding address density; SAD; den Dulk et al. 1992). To calculate this measure per neighborhood, the SAD is first calculated for each address in the neighborhood, subsequently the mean SAD of all addresses in a neighborhood is computed. Statistics Netherlands calculates this measure once per year. In the current study, we extracted the urbanicity measure for each neighborhood in our study, and averaged it across the 4 years $(2006,2007$, 2009, 2010) of the study.

Neighborhood socioeconomic status was indicated by several characteristics of the neighborhood: average value of housing, mean income of persons with an income, mean income per person, proportion of persons with a high 
income, proportion of economically inactive persons, proportion of individuals receiving social welfare, number of motor vehicles per household and proportion of individuals with a non-western immigrant background. A principle components analysis of these variables was run for each year in order to summarize them. This resulted in two components, employment and income, which explained between $71-72 \%$ and $14-16 \%$ of the variance, respectively (employment $M=71 \%, \mathrm{SD}=1 \%$, income $M=15 \%$, SD $=1 \%$, total $M=87 \%, \mathrm{SD}=0 \%$ ). The factor scores per neighborhood had a mean of $0.02(\mathrm{SD}=1.02)$ and -0.00 $(\mathrm{SD}=1.04)$ for employment and income, respectively. The scores on each component were then averaged across the 4 years of the study.

\section{Family characteristics}

Family socioeconomic status was based on the occupations of the mother and father, reported by the primary caregiver in 2005 and 2007. Levels of occupation were assigned according to the Dutch Working Population Classifications of Occupations Scheme (Statistics Netherlands 2001). Occupations were classified into six categories and subsequently collapsed into three categories whereby a higher score indicated higher socioeconomic status $(0=$ low socioeconomic status or unemployed and lower-level occupations, e.g., bartender, receptionist; $1=$ average socioeconomic status or middle-level occupations, e.g., doctor's assistant; $2=$ high socioeconomic status or higherlevel and scientific occupations, e.g., elementary school teacher, clinical psychologist). We used the highest occupation of the mother or father reported in either year.

Parent symptoms of psychopathology was based on the Kessler Psychological Distress Scale (K-10; Kessler et al. 2002), a short screening questionnaire filled in by both parents in 2005 and by the primary caregiver in 2006 . The scale consists of 10 questions about how they felt in the past 30 days, rated on a five-point Likert scale. Questions were related to depressed mood, motor agitation, fatigue, feelings of worthlessness and anxiety. For the 2005 measurement, mothers' and fathers' scores were averaged. The mean of scores from the 2005 and 2006 measurements was then taken. The reliability of this scale in the current sample was good to excellent (2005 mother-report: Cronbach's $\alpha=.90$, 2005 father-report Cronbach's $\alpha=.88,2006$ : Cronbach's $\alpha=.92$ ).

Parenting stress was indexed by the Nijmegen Parenting Stress Index (De Brock et al. 1992). In 2005, the primary caregiver filled in the 11 items of the Parent Domain (e.g., Being a parent to this child is more difficult than I thought) and the 14 items of the Child Domain (e.g., My child seems to be more difficult to care for than most children), rated on a six-point Likert scale. In 2006, the primary caregiver filled in the items on the Parent Domain only. For each year, the mean of the scores on all items was taken as an indication of the parenting stress experienced. These scores were then averaged across the two measurements. The reliability of this scale in the current sample was good to excellent (2005: Cronbach's $\alpha=.92$, 2006: Cronbach's $\alpha=.87$ ).

Parenting practices were indicated by a composite score of two measures of parenting practices. Two subscales of the Alabama Parenting Questionnaire (APQ; Essau et al. 2006) were completed by the primary caregiver in 2005 and 2006. The 10 items of the Involvement and Poor Monitoring subscales were answered on a five-point Likert scale. The other subscales of the APQ (i.e., Positive Reinforcement, Inconsistent Discipline and Harsh Discipline) were not administered due our focus on parenting techniques and not discipline, and to minimize the participant burden. For the current analyses, all items of the Involvement subscale were reverse coded to reflect less optimal parenting (in order to maintain consistency with the other subscales). The primary caregiver also filled in the Parenting Scale (Arnold et al. 1993) during the same years. This scale has 30 items on three subscales, i.e., Laxness, Overreactivity, and Verbosity. All 30 items were completed in 2005, and 15 items were completed in 2006 (the Verbosity subscale was taken out of the questionnaire packet in 2006). In the current study, we used the general measure of Dysfunctional Parenting (all items). For each year, the mean of all items for each (sub)scale was calculated (i.e., Involvement, Poor Monitoring and all items of the Parenting Scale). The mean scores were subsequently standardized, after which the standardized means of all (sub)scales were averaged to a general measure of parenting practices, with greater scores indicating less optimal parenting practices (i.e., less involvement and a higher degree of poor monitoring, laxness, overreactivity and verbosity). This was done for both years; the mean of both years was then taken. The reliability for most of the subscales was acceptable to good (Involvement: .78 and .82, Poor Monitoring: .73 and .63, Dysfunctional Parenting: .76 and .70, for 2005 and 2006, respectively).

\section{Individual characteristics}

Child gender $(0=$ male, $1=$ female $)$ and ethnicity $(0=$ Dutch, $1=$ non-western immigrant background) were reported by the primary caregiver in 2005. Children were considered to have a non-western immigrant background if they or one of their parents were born in a non-western country. No children had a western immigrant background. Because some children participated in a classroom-level intervention in 2005 and 2006 (see 'Procedure' section) intervention status $(0=$ control, $1=$ intervention), was controlled in all analyses. 


\section{Data Analyses}

\section{Available data}

The larger study from which the data for the current analyses were taken was conducted from 2004 until 2011, with data collection waves once or twice a year. In total, $n=$ 1084 children consented to participate in at least one of the data collection waves. The focus of the current study was on elementary school children, therefore we used data from when children were aged 8, 9, 11 and 12 years (calendar years 2006, 2007, 2009, 2010). Kindergarten classes were recruited in 2004. These classes were then followed, largely consisting of the same individuals, although through the years some children moved to different classrooms or schools, and other children entered the participating classrooms. When their parents and their teacher consented, children who moved out of a participating classroom were also followed to their new classroom, and in some cases the other children in the new classroom also entered the study (see Supplementary Figure 1 for a flowchart of the study sample). Data were considered complete for each participant if there was information on the home address of the participant as well as teacher-reported information on behavioral and emotional problems. If, for any year, information on behavioral and emotional problems was known, but the participant's home address was not, the outcome data were considered missing. During the course of the study, six participants moved between 2006 and 2007; no one moved (and remained in the study) between any other years. For these six participants, all data from 2006 were considered missing because the 2006 neighborhood data differed from the 2007-2010 neighborhood data.

During the four years of data collection that we included in our study, $N=1027$ children participated during at least one of these years. Of these children, information on behavioral and emotional problems was available for $N=$ 1011 children. Of these children, home address data were available for $N=936$ children. Because we were interested in associations between neighborhood-level variables and individual outcomes, we excluded all neighborhoods in which only one participant lived $(n=41)$, which led to our final sample for the main analysis of $N=895$. Children who were included in the final sample $(N=895)$ exhibited fewer teacher-reported behavioral $(t=3.57, p<.001)$ and emotional $(t=3.78, p<.001)$ problems, and were more likely to have Dutch ethnicity $\left(\chi^{2}=4.57, p=.03\right)$ and to have participated in the intervention $\left(\chi^{2}=7.76, p=.01\right)$ compared to those who participated in the study but were not included in the final sample $(N=132)$. These samples did not differ regarding gender and family socioeconomic status. In the final sample $(N=895)$, data were available for $53 \%$ of the children for all 4 years (3 years: 15\%, 2 years: $23 \%, 1$ year:
9\%). Parent data (for at least one measure) were available for $74 \%$ of the sample, which led to our final samples of $n$ $=617$ regarding family socioeconomic status and $n=435$ regarding all other parental variables.

Our complete sample of $N=895$ participants was from 30 schools and 32 neighborhoods. On average, there were 30 participants from each school (range $=9-126$ ). These schools were distributed across 19 neighborhoods. Seventynine percent of the participants lived and went to school in the same neighborhood. Each neighborhood was home to between 2 and 128 participants $(M=28)$, and $69 \%$ of the neighborhoods were home to at least 10 participants. On average, the neighborhoods in our study were more urban than the Netherlands as a whole (average SAD in the current sample $=3589$ addresses; average SAD of the Netherlands during the years that the study took place $=1890$ addresses).

\section{Analyses}

All variables were averaged across the 4 years of the study (or 2 years in the case of family characteristics) in order to obtain robust measures. We calculated descriptive statistics and zero-order correlations. Subsequently, all variables were centered and scaled in order to facilitate comparison of the coefficients. Intraclass correlations were calculated with the package multilevel (Bliese 2013) in R (2015).

Models were specified with the pbkrtest package (Halekoh and Hojsgaard 2014), which depends on the lme4 package (Bates et al. 2011) in R (2015). The structure of our data was such that individuals were nested within neighborhoods and schools, which were cross-nested. We specified separate models for behavioral and emotional problems. We began by specifying empty models with a random intercept for school (i.e., we specified one empty model with the outcome of behavioral problems, and one empty model with the outcome of emotional problems). We then examined whether including a random intercept for neighborhood improved the model significantly. If this was the case, the random intercept was retained in the model.

We ran a series of linear mixed effects models to determine whether urbanicity was significantly associated with behavioral and emotional problems, and whether this remained so when controlling for the other risk factors. We first added (clusters of) the risk factors in a stepwise, additive manner, and as the last part of each step we entered urbanicity to determine whether it remained significantly associated with behavioral and emotional problems while controlling for the other risk factors. We used the 'mixed' call in 'pbkrtest', and $F$ tests and degrees of freedom were based on the Kenward Rogers approximation (method= KR; Halekoh and Hojsgaard 2014). We compared models with and without urbanicity included using $-2 \log$ 
likelihood statistics. Specifically, in the first set of models, we included only the predictor urbanicity (Step I). In the second set of models, we added neighborhood socioeconomic status: employment and neighborhood socioeconomic status: income (Step II). Then, we added individual characteristics (i.e., child gender and ethnicity; Step III). In Step IV we added family socioeconomic status and in Step $\mathrm{V}$ we added parental symptoms of psychopathology, parenting stress and parenting practices. We controlled for intervention status in all models. In each model, coefficients were considered statistically significant at $p<.05$.

\section{Results}

Descriptive statistics and correlations between study variables are given in Tables 1 and 2, respectively. All variables were normally distributed, except parent psychopathology (skewness $=2.39, \mathrm{SE}=0.11$; kurtosis $=9.43, \mathrm{SE}=0.23$ ) and parenting stress (skewness $=1.46, \mathrm{SE}=0.11$; kurtosis $=2.97, \mathrm{SE}=0.23$ ). Behavioral and emotional problems were strongly and positively correlated. Parental variables were available for a subsample of participants, therefore complete data for all variables as tested in the final models were available for a subsample $(n=435)$ of the entire sample $(N=895)$. We examined whether participants who were in this subsample differed from those who were not. Subsample participants had fewer behavioral and emotional problems, were from neighborhoods that were less urban and had a higher socioeconomic status (employment component only), were more likely to be of Dutch ethnicity and from a family with high socioeconomic status, and were more likely to have participated in the intervention compared to those who were not included in the final models (see Supplementary Table 1).

\section{Preliminary Models}

Participants were clustered by school and neighborhood. We defined the empty models for behavioral problems and emotional problems separately. We first included a random intercept for school, which significantly improved the fit of the models. Subsequently, we added a level for neighborhood, but this did not improve the models significantly. Therefore, we estimated two-level models with participants at the first level and school at the second level.

We calculated intraclass correlations (ICC) using the empty models as indications of reliability. The ICC1 indicates the percentage of variance in behavioral and emotional problems that can be explained by group membership. ICC1 statistics were higher for school than for neighborhood. These, as well as the statistics for the fixed and random effects, are given in Table 3. The ICC2 is an indication of reliability and should be $>.70$ (Bliese 2000). In the empty models for both behavioral and emotional problems, the ICC2 was only $>.70$ for the school cluster. This is consistent with the finding described above that adding a random intercept for neighborhood did not improve the empty models significantly.

Table 1 Descriptive statistics of study variables

\begin{tabular}{|c|c|c|c|c|c|c|c|c|c|}
\hline \multirow[b]{2}{*}{ Variable } & \multirow[b]{2}{*}{$n$} & \multirow[b]{2}{*}{ Min } & \multirow[b]{2}{*}{ Max } & \multirow[b]{2}{*}{ Mean $/ F$} & \multirow[b]{2}{*}{ SD } & \multicolumn{2}{|c|}{ Skewness } & \multicolumn{2}{|c|}{ Kurtosis } \\
\hline & & & & & & Est & SE & Est & SE \\
\hline Behavioral problems & 895 & 0 & 3.13 & 0.76 & 0.58 & 0.98 & 0.08 & 0.59 & 0.16 \\
\hline Emotional problems & 895 & 0 & 3.01 & 0.90 & 0.45 & 0.69 & 0.08 & 0.59 & 0.16 \\
\hline Urbanicity & 895 & 770.25 & 8230.33 & 3287.50 & 2041.70 & 0.62 & 0.08 & -0.80 & 0.16 \\
\hline SES employment & 895 & -1.69 & 1.65 & 0.06 & 0.98 & -0.12 & 0.08 & -1.59 & 0.16 \\
\hline SES income & 895 & -2.28 & 1.72 & -0.10 & 0.97 & 0.39 & 0.08 & -1.03 & 0.16 \\
\hline Gender (male/female) & 895 & & & $49 / 51$ & & & & & \\
\hline $\begin{array}{l}\text { Ethnicity (Dutch/non-western } \\
\text { immigrant) }\end{array}$ & 726 & & & $63 / 37$ & & & & & \\
\hline Family SES (low/average/high) & 659 & & & $32 / 29 / 39$ & & & & & \\
\hline Parent psychopathology & 455 & 0 & 40 & 5.80 & 5.52 & 2.39 & 0.11 & 9.43 & 0.23 \\
\hline Parenting stress & 470 & 0 & 4.44 & 0.88 & 0.68 & 1.46 & 0.11 & 2.97 & 0.23 \\
\hline Parenting practices & 489 & -1.69 & 3.25 & 0.00 & 0.70 & 0.46 & 0.11 & 0.80 & 0.22 \\
\hline $\begin{array}{l}\text { Intervention status (intervention/ } \\
\text { control) }\end{array}$ & 895 & & & $39 / 61$ & & & & & \\
\hline
\end{tabular}

Note: Neighborhood urbanicity is based on the surrounding address density. Urbanicity, SES employment and SES income were measured at the neighborhood level. Higher scores on parenting practices indicate less optimal parenting practices

$F$ frequency (\%), SD standard deviation, Est estimate, SE standard error, SES socioeconomic status 
Table 2 Spearman's zero-order correlations between study variables

\begin{tabular}{|c|c|c|c|c|c|c|c|c|c|c|c|c|}
\hline & 1 & 2 & 3 & 4 & 5 & 6 & 7 & 8 & 9 & 10 & 11 & 12 \\
\hline 1. Behavioral problems & - & .59 & .25 & -.23 & -.09 & -.26 & .31 & -.23 & .15 & .20 & .15 & -.03 \\
\hline 2. Emotional problems & & - & .21 & -.17 & -.07 & -.15 & .18 & -.17 & .15 & .13 & .05 & -.07 \\
\hline 3. Urbanicity & & & - & -.81 & -.37 & .06 & .55 & -.28 & .08 & .17 & .13 & -.07 \\
\hline 4. SES employment & & & & - & .63 & -.05 & -.59 & .35 & -.05 & -.17 & -.17 & .04 \\
\hline 5. SES income & & & & & - & -.04 & -.40 & .39 & -.00 & -.07 & -.15 & .25 \\
\hline 6. Gender & & & & & & - & .04 & -.01 & -.04 & -.01 & -.06 & -.05 \\
\hline 7. Ethnicity & & & & & & & - & -.50 & .09 & .10 & .17 & -.15 \\
\hline 8. Family SES & & & & & & & & - & -.13 & -.09 & -.18 & .20 \\
\hline 9. Parent psychopathology & & & & & & & & & - & .41 & .23 & -.07 \\
\hline 10. Parenting stress & & & & & & & & & & - & .37 & .04 \\
\hline 11. Parenting practices & & & & & & & & & & & - & -.05 \\
\hline 12. Intervention status & & & & & & & & & & & & - \\
\hline
\end{tabular}

Note: Italics $=p<.05 ;$ bold $=p<.001$. Urbanicity, SES employment and SES income were measured at the neighborhood level. Higher scores on parenting practices indicate less optimal parenting practices

SES socioeconomic status

\section{Urbanicity}

We first examined whether living in a more urban area was significantly associated with more behavioral and emotional problems in children. Results from these first models (see Table 3) showed that children who lived in more urban areas during elementary school were more likely to show behavioral and emotional problems as reported by their teachers. Figure 1 depicts the average scores for behavioral and emotional problems per neighborhood, divided into neighborhoods with a low SAD ( $-1 \mathrm{SD})$, medium SAD and high SAD (+1SD).

\section{Control Variables}

We then examined whether urbanicity was associated with behavioral and emotional problems while controlling for other major risk factors. Results from the second set of models showed that urbanicity remained significantly associated with behavioral and emotional problems when controlling for both components (employment and income) of neighborhood socioeconomic status. Results from Step III showed that urbanicity was associated with behavioral and emotional problems when additionally controlling for gender and ethnicity. Results from Step IV showed that urbanicity was significantly associated with behavioral problems when additionally controlling for family socioeconomic status. In the model predicting emotional problems, urbanicity was no longer a significant predictor $(p$ $=.05$ ). In the final models, we included all abovementioned predictors as well as three parent characteristics: parent symptoms of psychopathology, parenting stress and parenting practices. In these models (Step V), urbanicity remained significantly associated with behavioral and emotional problems. Intervention status was controlled in all models and was never significantly associated with behavioral or emotional problems.

\section{Discussion}

In the current study, we investigated whether children living in more urban areas were more likely to exhibit behavioral and emotional problems. The results showed that neighborhood-level urbanicity was associated with more behavioral and emotional problems, as reported by the children's teachers. Importantly, urbanicity remained significantly associated with behavioral and emotional problems when controlling for other major risk factors for mental health problems in children, that is, two components of neighborhood-level socioeconomic status (employment and income), gender, ethnicity, family-level socioeconomic status, parental symptoms of psychopathology, parenting stress and parenting practices. There was one exception: when family socioeconomic status was included in the model the association between urbanicity and emotional problems was only marginally significant.

Earlier studies posited that effects of urbanicity on mental health problems may be due to selective migration, or the tendency of vulnerable individuals to migrate to urban areas (Dunham 1965). However, empirical evidence against this hypothesis has accumulated and provided increasing support for urban-living as an independent risk factor for mental health problems (e.g., Marcelis et al. 1998; Krabbendam and van Os 2005; Pedersen and Mortensen 2001). The current view holds that a greater demand for 
Table 3 Unstandardized coefficients and variance components for all mixed effects models

\begin{tabular}{|c|c|c|c|c|c|c|c|c|c|c|}
\hline & \multicolumn{5}{|c|}{ Behavioral problems } & \multicolumn{5}{|c|}{ Emotional problems } \\
\hline & \multicolumn{4}{|c|}{ Fixed effects } & \multirow[t]{2}{*}{$\chi^{2}$} & \multicolumn{4}{|c|}{ Fixed effects } & \multirow[t]{2}{*}{$\chi^{2}$} \\
\hline & Est & SE & $F$ & $p$ & & Est & SE & $F$ & $p$ & \\
\hline \multicolumn{11}{|l|}{ I. Urbanicity } \\
\hline Urbanicity & 0.23 & 0.05 & 21.62 & $<.001$ & $14.34 * * *$ & 0.23 & 0.06 & 14.29 & $<.001$ & $10.36^{* *}$ \\
\hline \multicolumn{11}{|l|}{ II. Neighborhood } \\
\hline SES employment & 0.02 & 0.10 & 0.02 & .88 & & 0.09 & 0.11 & 0.59 & .44 & \\
\hline SES income & 0.02 & 0.06 & 0.13 & .72 & & -0.03 & 0.08 & 0.12 & .73 & \\
\hline Urbanicity & 0.25 & 0.08 & 8.62 & .005 & $5.81^{*}$ & 0.29 & 0.10 & 8.51 & .004 & $5.80^{*}$ \\
\hline \multicolumn{11}{|l|}{ III. Individual } \\
\hline SES employment & 0.11 & 0.10 & 1.20 & .28 & & 0.12 & 0.12 & 0.98 & .32 & \\
\hline SES income & 0.02 & 0.06 & 0.08 & .78 & & 0.00 & 0.08 & 0.00 & .99 & \\
\hline Gender & -0.56 & 0.06 & 75.80 & $<.001$ & & $-\mathbf{0 . 3 3}$ & 0.07 & 24.39 & $<.001$ & \\
\hline Ethnicity & 0.37 & 0.10 & 14.93 & $<.001$ & & -0.01 & 0.10 & 0.01 & .94 & \\
\hline Urbanicity & 0.28 & 0.08 & 10.69 & .002 & $7.92 * *$ & 0.34 & 0.10 & 9.86 & .002 & $7.04 * *$ \\
\hline \multicolumn{11}{|l|}{ IV. Family } \\
\hline SES employment & 0.11 & 0.11 & 1.13 & .29 & & 0.11 & 0.13 & 0.66 & .42 & \\
\hline SES income & 0.03 & 0.07 & 0.20 & .66 & & 0.00 & 0.08 & 0.00 & .96 & \\
\hline Gender & -0.58 & 0.07 & 74.15 & $<.001$ & & -0.32 & 0.07 & 21.86 & $<.001$ & \\
\hline Ethnicity & 0.31 & 0.11 & 8.22 & .004 & & 0.06 & 0.11 & 0.32 & .57 & \\
\hline Low family SES & 0.39 & 0.10 & 7.89 & $<.001$ & & 0.32 & 0.10 & 6.75 & .001 & \\
\hline Average family SES & 0.22 & 0.09 & - & - & & 0.28 & 0.09 & - & - & \\
\hline Urbanicity & 0.26 & 0.09 & 7.68 & .008 & $5.01 *$ & 0.23 & 0.11 & 4.03 & .05 & 1.41 \\
\hline \multicolumn{11}{|l|}{ V. Parental variables } \\
\hline SES employment & 0.14 & 0.12 & 1.30 & .26 & & 0.24 & 0.14 & 2.81 & .10 & \\
\hline SES income & 0.05 & 0.08 & 0.48 & .49 & & -0.00 & 0.09 & 0.00 & .96 & \\
\hline Gender & -0.59 & 0.08 & 53.74 & $<.001$ & & -0.41 & 0.08 & 24.54 & $<.001$ & \\
\hline Ethnicity & 0.37 & 0.14 & 6.32 & .01 & & 0.12 & 0.15 & 0.60 & .44 & \\
\hline Low family SES & 0.37 & 0.13 & 4.33 & .01 & & 0.19 & 0.13 & 2.55 & .08 & \\
\hline Average family SES & 0.17 & 0.10 & - & - & & 0.24 & 0.11 & - & - & \\
\hline Psychopathology & 0.05 & 0.05 & 1.29 & .26 & & 0.09 & 0.05 & 3.91 & .05 & \\
\hline Stress & 0.14 & 0.05 & 8.08 & .005 & & 0.14 & 0.05 & 7.91 & .005 & \\
\hline Parenting practices & -0.01 & 0.05 & 0.10 & .75 & & -0.09 & 0.05 & 3.15 & .08 & \\
\hline \multirow[t]{3}{*}{ Urbanicity } & 0.26 & 0.11 & 5.74 & .02 & 3.05 & 0.35 & 0.12 & 7.41 & .009 & $4.78^{*}$ \\
\hline & \multicolumn{5}{|c|}{ Random effects } & \multicolumn{5}{|c|}{ Random effects } \\
\hline & \multicolumn{3}{|c|}{ Variance } & \multicolumn{2}{|l|}{ SD } & \multicolumn{3}{|c|}{ Variance } & \multicolumn{2}{|l|}{$\mathrm{SD}$} \\
\hline School & \multicolumn{3}{|c|}{0.06} & \multicolumn{2}{|l|}{0.25} & \multicolumn{3}{|c|}{0.14} & \multicolumn{2}{|l|}{0.37} \\
\hline \multirow[t]{3}{*}{ Residual } & 0.89 & & & 0.94 & & 0.86 & & & 0.93 & \\
\hline & Intracla & relatio & & & & Intracla & relatio & & & \\
\hline & School & & & Nbh & & School & & & Nbh & \\
\hline ICC1 & .12 & & & .09 & & .17 & & & .10 & \\
\hline ICC2 & .75 & & & .61 & & .82 & & & .64 & \\
\hline
\end{tabular}

Note: The statistics for each model are from the model including urbanicity. $\chi^{2}$ statistics use $-2 \log$ likelihood estimates to compare the model without urbanicity and the model with urbanicity included $(d f=1)$. Urbanicity, SES employment and SES income were measured at the neighborhood level. Gender was coded as $0=$ male, $1=$ female; ethnicity as $0=$ Dutch, $1=$ non-western immigrant background. Statistics for low and average family SES are in comparison to high family SES. Higher scores on parenting practices indicate less optimal parenting practices. Random effects were based on the models in Step I. ICC statistics were calculated using the empty models. The $n$ of the first (individual) level differed per step: I-II: $N=895$; III: $n=726$; IV: $n=617$; VI: $n=435$. The $N$ of the second (school) level was always 30

Est estimate, $S E$ standard error, $S D$ standard deviation, ICC intraclass correlations, Nbh neighborhood, SES socioeconomic status bold $=p<.05$ (fixed effects); $*^{* *} p<.001 ; * * p<.01 ; * p<.05\left(\chi^{2}\right.$ statistics $)$

social stress processing in cities may be the fundamental underlying mechanism (Mizrahi 2016). Social stress is a powerful stressor elicited by, for example, a crowded environment (Schwab et al. 1979), greater anonymity
(Leviton et al. 2000), competition for resources (Selten and Cantor-Graae 2005), perceived isolation (Van Os et al. 2000), encounters with strangers and unclear dominance order (Zayan 1991). These factors can increase the threat of 


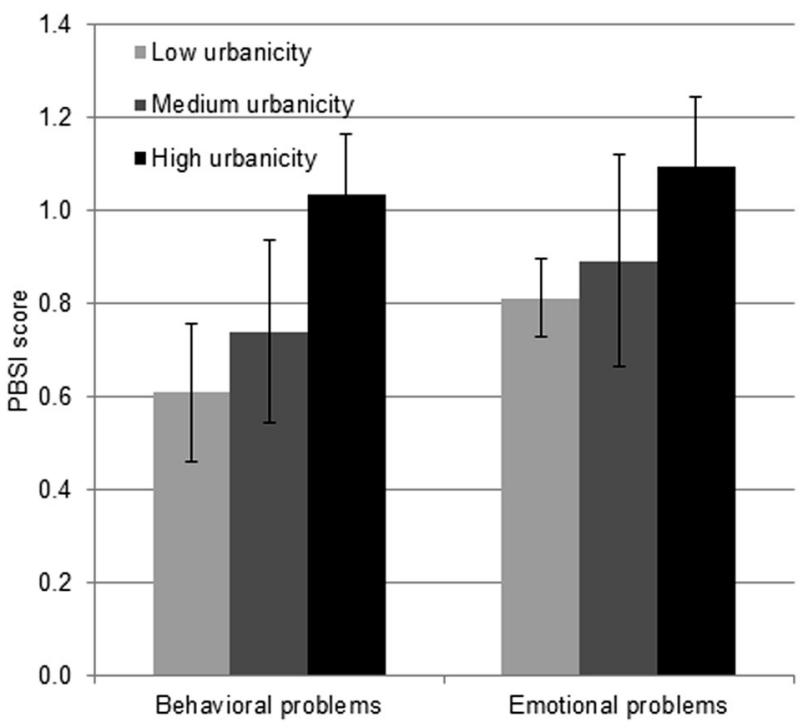

Fig. 1 Behavioral and emotional problems per neighborhoods with low, medium and high urbanicity (surrounding address density). Note. PBSI Problem Behavior at School Interview, SAD surrounding address density. Low/high surrounding address density corresponds to 1 standard deviation below/above the average. Averages were first calculated per neighborhood. Error bars indicate standard deviations. There were $n=5$ low SAD neighborhoods, $n=20$ medium and $n=7$ high

social evaluation (Leary and Baumeister 2000) and defeat (Selten and Cantor-Graae 2005).

There may be evidence underscoring the notion that heightened social stress processing in city-dwellers indeed underlies the association between urbanicity and mental health problems. A functional neuroimaging study showed that adults who grew up in cities responded differently to social stress compared to those who grew up in towns or rural areas (Lederbogen et al. 2011). In another study, urban upbringing in adults was associated with dysregulated biological stress responses (Steinheuser et al. 2014). In youth, there is also beginning evidence that living in more urban areas is related to dysregulated biological stress system functioning (Evans et al. 2013). Our study highlights the need for further research that contributes to understanding how urbanicity is associated with mental health.

Our study extends the findings from previous research by demonstrating that living in more urban areas may be associated with subclinical mental health problems. Most previous research examined the association between urbanicity and psychiatric disorders in children (e.g., Lauritsen et al. 2014) and adults (Peen et al. 2010). The current study and a recent British study (Newbury et al. 2016) showed that living in a more urban area was also associated with exhibiting more symptoms of psychiatric disorders. Related research furthermore showed that children living in more urban areas were more likely to have intellectual disabilities (Rutter 1981) and poorer academic achievement (Votruba-
Drzal et al. 2016; Miller et al. 2013) than their rural counterparts. As these subclinical mental health and developmental problems affect a much larger portion of the population than clinical psychiatric disorders, the current findings underscore the importance of further research regarding mechanisms underlying the association between urbanicity and development as well as research on how to begin to dismantle this association, for example, by connecting child development research to research on urban design.

Considering that previous studies found associations between urbanicity and a wide range of psychiatric disorders (see Rutter 1981; Peen et al. 2010), we chose to examine the broader dimensions of behavioral and emotional problems, also often referred to as externalizing and internalizing problems, respectively. Behavioral and emotional problems have been shown to reflect the underlying dimensions of psychiatric disorders (Achenbach and Edelbrock 1978; Carragher et al. 2015). Although some have suggested a general $p$ factor for psychiatric disorders (Caspi et al. 2014; Lahey et al. 2011), consensus seems to converge on the two-dimensional structure. This structure holds across various subpopulations based on age (Eaton et al. 2011), gender (Eaton et al. 2012), ethnicity (Eaton et al. 2013) and culture (Kessler et al. 2011), and has been confirmed by genetic studies (Kendler et al. 2011; Rhee et al. 2015). Behavioral and emotional problems are certainly linked, as co-occurrence of these dimensions is common (Lilienfeld 2003). However, it is clear that the dimensions are also distinct, with the differences seeming to be associated with personality factors: behavioral problems are characterized by disinhibitory personality traits (Krueger and South 2009) whereas emotional problems are commonly typified by negative affect (Kendler and Myers 2014). In line with this previous research, behavioral and emotional problems were positively correlated in our study.

Urbanicity was associated with both behavioral and emotional problems in the current study, and this remained so when controlling for several other neighborhood- familyand individual-level factors. Although this is an important step in understanding the association between urbanicity and mental health, it is much too simplified. Neighborhood, family, and individual processes are inter-related and have bi-directional influences on each other (Leventhal et al. 2016; Mulatu and Schooler 2002). For example, as suggested in the reports of the Isle of Wight studies, the effects of urbanicity on children's mental health may operate through parents and families (Rutter 1981). Evidence from a similar line of research likewise indicated that family factors such as socioeconomic status (Reijneveld et al. 2010) and parenting (Odgers et al. 2012) mediated the effects of neighborhood socioeconomic status on children's behavioral problems, although other studies found neighborhood 
effects to function over and above family- and individuallevel effects on behavioral problems (Kalff et al. 2001). Relatedly, socioeconomic status may moderate (Rudolph et al. 2014) or mediate (Kovess-Masfety et al. 2005) the association between urbanicity and emotional problems. Furthermore, researchers have found that individual factors such as temperament mediated neighborhood influences on mental health (Bush et al. 2010) and that specific neighborhood factors such as social cohesion and social control mediated the effects of urbanicity on psychotic symptoms (Newbury et al. 2016). Thus, it is inferable that the associations between urbanicity and mental health operate through and are modified by various neighborhood- familyand individual level factors. Our study can therefore be seen as a stepping stone to further studies that will delineate more specific pathways between urbanicity and mental health.

Across the world, urbanization is steadily increasing (United Nations 2014), and because of this, there is an urgent need to fully grasp the way in which living in more urban areas affects youth's development. First, we need to shed more light on the causality of urbanicity in influencing underlying mechanisms and mental health measures. Several studies provided evidence for a dose-response relation between urbanicity and psychiatric disorders (e.g., Pedersen and Mortensen 2001; Lauritsen et al. 2014) which suggests causality (Hill 1965). Further studies are needed that track individuals, more preferably families, from birth while including data on potential underlying mechanisms between urbanicity and mental health problems. Importantly, more effort needs to be undertaken to combine and share findings across disciplines (i.e., developmental psychology, sociology, public health), and to extend these findings in order to inform public policy. For example, a recent surge of research showed that there may be beneficial effects for mental health of living near green spaces within urban areas (Flouri et al. 2014). This research can guide public officials in designing and developing public spaces, such as neighborhoods (Hartig and Kahn 2016), and playgrounds (Bagot et al. 2015).

\section{Limitations}

The results of our study should be considered in light of the following. We used a cross-sectional design, averaging all variables across 5 years during elementary school. We chose to perform the analyses with this design because we were not interested in the development of behavioral and emotional problems over time, in relation to urbanicity. In this initial study, our goal was to assess the association between urbanicity and mental health in children while controlling for other important risk factors for mental health problems. It is important to keep in mind that our sample was fairly urban in comparison to the Netherlands as a whole. We used the continuous measure of surrounding address density (as opposed to a categorical measure as is sometimes employed) in order to take full advantage of the variance in urbanicity in our sample. The findings, however, may not be generalizable to more rural samples, and further research is needed to confirm these findings in other samples. Also, we used 'administrative' neighborhoods as defined by Statistics Netherlands in order to obtain objective measures of the neighborhood. Neighborhoods are defined based on areas with a homogenous socioeconomic structure (Statistics Netherlands 2016), however, they may differ from 'natural' neighborhoods, or neighborhoods as perceived by the inhabitants, which may be more ecologically valid. Another limitation is that children's behavioral and emotional problems were assessed by a single informant. We used teachers' reports on the Problem Behavior at School Interview because it was consistently implemented (i.e., for all children and across all years of the study). A number of additional questionnaires that assessed behavioral and emotional problems were administered during some years of the study to teachers, parents and classmates, and these data largely coincided with the teacher reports used in the current study (data available upon request). Also, two of our predictors (parent psychopathology and parenting stress) were skewed. Although the extreme values of these predictors may have a disproportionate effect on the regression coefficients, regression analyses in large samples such as ours are fairly robust against assumptions of normality (Lumley et al. 2002). In addition, although we assessed a number of factors that could explain the association between urbanicity and behavioral and emotional problems in children, there are other factors that could explain this association that were not included in our study, such as neighborhood social cohesion and social control (Newbury et al. 2016), or excessive noise levels (Pujol et al. 2014). In addition, we did not account for comorbidity, as we examined behavioral and emotional problems in separate models. Finally, we did not test for moderation or mediation effects, as this was beyond the scope of the current study. However, as discussed above, urbanicity is likely to be associated with mental health via or modified by other neighborhood-, family- and individual-level factors, and this would be an interesting avenue for further research.

Acknowledgements We would like to thank all participants of the Spelregels study, their parents and teachers. This study was financially supported by the Netherlands Organization for Health Research and Development Grants \#26200002 and \#120620029.

Author Contributions B.E.: designed the research questions for the current study, performed the data analyses and wrote the paper. J.B.: assisted with the data analyses, collaborated with the writing of the methods and results and collaborated with the editing of the final manuscript. W.B.: collaborated with the design of the research questions, assisted with the data analyses and collaborated with the editing 
of the final manuscript. A.C.: collaborated with the writing and editing of the final manuscript. P.L.: acquired funding for the larger study of which the current study was a part, designed the larger study, collaborated with the design of the current research questions and collaborated with the writing and editing of the final manuscript.

\section{Compliance with Ethical Standards}

Conflict of Interest The authors declare that they have no conflict of interest.

Informed Consent The parents of all children included in the study gave informed consent at the beginning of their child's participation in the study. For each subsequent data collection wave, parents were informed of the data collection plans and were given the opportunity to revoke the inclusion of their child or themselves in the study.

\section{References}

Achenbach, T. M., \& Edelbrock, C. S. (1978). Classification of child psychopathology - Review and analysis of empirical effors. Psychological Bulletin, 85(6), 1275-1301. https://doi.org/10. 1037//0033-2909.85.6.1275.

Amrock, S. M., \& Weitzman, M. (2014). Parental psychological distress and children's mental health: Results of a national survey. Academic Pediatrics, 14(4), 375-381.

Arnold, D. S., O’Leary, S. G., Wolff, L. S., \& Acker, M. M. (1993). The Parenting Scale: A measure of dysfunctional parenting in discipline situations. Psychological Assessment, 5(2), 137-144.

Ashford, J., Smit, F., van Lier, P. A. C., Cuijpers, P., \& Koot, H. M. (2008). Early risk indicators of internalizing problems in late childhood: A 9-year longitudinal study. Journal of Child Psychology and Psychiatry, 49(7), 774-780. https://doi.org/10.1111/ j.1469-7610.2008.01889.x.

Bagot, K. L., Allen, F. C. L., \& Toukhsati, S. (2015). Perceived restorativeness of children's school playground environments: Nature, playground features and play period experiences. Journal of Environmental Psychology, 41, 1-9. https://doi.org/10.1016/j. jenvp.2014.11.005.

Bates, D., Maechler, M., \& Bolker, B. (2011). lme4: Linear mixedeffects models using S4 classes. (R package version 0.999375-42 ed.).

Bayer, J. K., Hiscock, H., Ukoumunne, O. C., Price, A., \& Wake, M. (2008). Early childhood aetiology of mental health problems: A longitudinal population-based study. Journal of Child Psychology and Psychiatry, 49(11), 1166-1174. https://doi.org/10.1111/j. 1469-7610.2008.01943.x

Beardslee, W. R., Versage, E. M., \& Gladstone, T. R. G. (1998). Children of affectively ill parents: A review of the past 10 years. Journal of the American Academy of Child and Adolescent Psychiatry, 37(11), 1134-1141. https://doi.org/10.1097/ 00004583-199811000-00012.

Bliese, P. (2000). Within-group agreement, non-independence, and reliability: Implications for data aggregation and analysis. In K. J. Klein \& S. W. Kozlowski (Eds.), Multilevel theory, research, and methods in organizations (pp. 349-381). San Francisco, CA: Jossey-Bass, Inc.

Bliese, P. (2013). Multilevel: Multilevel Functions. R Package version 2.5.

Bongers, I. L., Koot, H. M., van der Ende, J., \& Verhulst, F. C. (2003). The normative development of child and adolescent problem behavior. Journal of Abnormal Psychology, 112(2), 179-192. https://doi.org/10.1037/0021-843x.112.2.179.
Bush, N. R., Lengua, L. J., \& Colder, C. R. (2010). Temperament as a moderator of the relation between neighborhood and children's adjustment. Journal of Applied Developmental Psychology, 31 (5), 351-361. https://doi.org/10.1016/j.appdev.2010.06.004.

Carragher, N., Krueger, R. F., Eaton, N. R., \& Slade, T. (2015). Disorders without borders: Current and future directions in the meta-structure of mental disorders. Social Psychiatry and Psychiatric Epidemiology, 50(3), 339-350. https://doi.org/10.1007/ s00127-014-1004-z.

Caspi, A., Houts, R. M., Belsky, D. W., Goldman-Mellor, S. J., Harrington, H., \& Israel, S., et al. (2014). The p factor: One general psychopathology factor in the structure of psychiatric disorders? Clinical Psychological Science, 2(2), 119-137. https:// doi.org/10.1177/2167702613497473.

Caspi, A., Taylor, A., Moffitt, T. E., \& Plomin, R. (2000). Neighborhood deprivation affects children's mental health: Environmental risks identified in a genetic design. Psychological Science, 11(4), 338-342. https://doi.org/10.1111/1467-9280.00267.

Chen, C. Y., Liu, C. Y., Su, W. C., Huang, S. L., \& Lin, K. M. (2007). Factors associated with the diagnosis of neurodevelopmental disorders: A population-based longitudinal study. Pediatrics, 119 (2), E435-E443. https://doi.org/10.1542/peds.2006-1477.

Cyril, S., Oldroyd, J. C. \& Renzaho, A. (2013). Urbanisation, urbanicity, and health: a systematic review of the reliability and validity of urbanicity scales. BMC Public Health, 13, 513. https:// doi.org/51310.1186/1471-2458-13-513.

De Brock, A. J. L. L., Vermulst, A. A., Gerris, J. R. M., \& Abidin, R. R. (1992). Nijmeegse Ouderlijke Stress Index (Nijmegen Parental Stress Index). Lisse: Swets \& Zeitlinger.

den Dulk, C. J., van de Stadt, H., \& Vliegen, J. M. (1992). Een nieuwe maatstaf voor stedelijkheid: De omgevingsadressendichtheid [A new measure for degree of urbanisation: The address density of the surrounding area]. Maandstatistiek van de Bevolking, 40, $14-27$.

Dingle, K., Alati, R., Williams, G. M., Najman, J. M., Bor, W., \& Clavarino, A. (2010). The ability of YSR DSM-oriented depression scales to predict DSM-IV depression in young adults: A longitudinal study. Journal of Affective Disorders, 121(1), 45-51.

Duncan, G. J., Magnuson, K., \& Votruba-Drzal, E. (2016). Children and socioeconomic status. In M. H. Bornstein \& T. Leventhal (Eds.), Handbook of child psychology and developmental science Vol.4 (pp. 534-574). Hoboken, New Jersey: Wiley.

Dunham, H. W. (1965). Community and Schizophrenia. Detroit, MI: Wayne State University Press.

Dye, C. (2008). Health and urban living. Science, 319(5864), 766-769. https://doi.org/10.1126/science.1150198.

Eaton, N. R., Keyes, K. M., Krueger, R. F., Balsis, S., Skodol, A. E., \& Markon, K. E., et al. (2012). An invariant dimensional liability model of gender differences in mental disorder prevalence: Evidence from a national sample. Journal of Abnormal Psychology, 121(1), 282-288. https://doi.org/10.1037/a0024780.

Eaton, N. R., Keyes, K. M., Krueger, R. F., Noordhof, A., Skodol, A. E., \& Markon, K. E., et al. (2013). Ethnicity and psychiatric comorbidity in a national sample: Evidence for latent comorbidity factor invariance and connections with disorder prevalence. Social Psychiatry and Psychiatric Epidemiology, 48(5), 701-710. https://doi.org/10.1007/s00127-012-0595-5.

Eaton, N. R., Krueger, R. F., \& Oltmanns, T. F. (2011). Aging and the structure and long-term stability of the internalizing spectrum of personality and psychopathology. Psychology and Aging, 26(4), 987-993. https://doi.org/10.1037/a0024406.

Erasmus University Medical Center. (2000). Problem Behavior at School Interview. Rotterdam: Department of Child and Adolescent Psychiatry, Erasmus University Medical Center. 
Essau, C. A., Sasagawa, S., \& Frick, P. J. (2006). Psychometric properties of the Alabama Parenting Questionnaire. Journal of Child and Family Studies, 15, 597-616.

Evans, B. E., Greaves-Lord, K., Euser, A. S., Tulen, J. H. M., Franken, I. H. A., \& Huizink, A. C. (2013). Determinants of physiological and perceived physiological stress reactivity in children and adolescents. PloS ONE, 8(4), e61724.

Flouri, E., Midouhas, E., \& Joshi, H. (2014). The role of urban neighbourhood green space in children's emotional and behavioural resilience. Journal of Environmental Psychology, 40, 179-186. https://doi.org/10.1016/j.jenvp.2014.06.007.

Halekoh, U., \& Hojsgaard, S. (2014). A Kenward-Roger approximation and parametric bootstrap method for tests in linear mixed models - The R package pbkrtest. Journal of Statistical Software, 59(9), 1-30.

Hartig, T., \& Kahn, P. H. (2016). Living in cities, naturally. Science, 352(6288), 938-940. https://doi.org/10.1126/science.aaf3759.

Hill, A. B. (1965). Environment and disease - Association or causation. Proceedings of the Royal Society of Medicine-London, 58 (5), 295-300.

Kalff, A. C., Kroes, M., Vles, J. S. H., Hendriksen, J. G. M., Feron, F. J. M., \& Steyaert, J., et al. (2001). Neighbourhood level and individual level SES effects on child problem behaviour: A multilevel analysis. Journal of Epidemiology and Community Health, 55(4), 246-250. https://doi.org/10.1136/jech.55.4.246.

Kendler, K. S., Aggen, S. H., Knudsen, G. P., Roysamb, E., Neale, M. C., \& Reichborn-Kjennerud, T. (2011). The structure of genetic and environmental risk factors for syndromal and subsyndromal common DSM-IV Axis I and All Axis II disorders. American Journal of Psychiatry, 168(1), 29-39. https://doi.org/10.1176/a ppi.ajp.2010.10030340.

Kendler, K. S., \& Myers, J. (2014). The boundaries of the internalizing and externalizing genetic spectra in men and women. Psychological Medicine, 44(3), 647-655. https://doi.org/10.1017/ s0033291713000585.

Kessler, R. C., Andrews, G., Colpe, L. J., Hiripi, E., Mroczek, D. K., \& Normand, S. L. T., et al. (2002). Short screening scales to monitor population prevalences and trends in non-specific psychological distress. Psychological Medicine, 32(6), 959-976. https://doi.org/10.1017/s0033291702006074.

Kessler, R. C., Ormel, J., Petukhova, M., McLaughlin, K. A., Green, J. G., \& Russo, L. J., et al. (2011). Development of lifetime comorbidity in the World Health Organization World Mental Health Surveys. Archives of General Psychiatry, 68(1), 90-100. https://doi.org/10.1001/archgenpsychiatry.2010.180.

Kovess-Masfety, V., Lecoutour, X., \& Delavelle, S. (2005). Mood disorders and urban/rural settings: Comparisons between two French regions. Social Psychiatry and Psychiatric Epidemiology, 40, 613-618.

Krabbendam, L., \& van Os, J. (2005). Schizophrenia and urbanicity: A major environmental influence - Conditional on genetic risk. Schizophrenia Bulletin, 31(4), 795-799. https://doi.org/10.1093/ schbul/sbi060.

Krueger, R. F., \& South, S. C. (2009). Externalizing disorders: Cluster 5 of the proposed meta-structure for DSM-V and ICD-11. Psychological Medicine, 39(12), 2061-2070. https://doi.org/10.1017/ s0033291709990328.

Lahey, B. B., Van Hulle, C. A., Singh, A. L., Waldman, I. D., \& Rathouz, P. J. (2011). Higher-order genetic and environmental structure of prevalent forms of child and adolescent psychopathology. Archives of General Psychiatry, 68(2), 181-189. https://doi.org/10.1001/archgenpsychiatry.2010.192.

Lai, D.-C., Tseng, Y.-C., Hou, Y.-M., \& Guo, H. R. (2012). Gender and geographic differences in the prevalence of autism spectrum disorders in children: Analysis of data from the national disability registry of Taiwan. Research in Developmental Disabilities, 33 (3), 909-915. https://doi.org/10.1016/j.ridd.2011.12.015.

Lauritsen, M. B., Astrup, A., Pedersen, C. B., Obel, C., Schendel, D. E., \& Schieve, L., et al. (2014). Urbanicity and autism spectrum disorders. Journal of Autism and Developmental Disorders, 44 (2), 394-404. https://doi.org/10.1007/s10803-013-1875-y.

Leary, M. R. \& Baumeister, R. F. (2000). The nature and function of self-esteem: Sociometer theory. Advances in Experimental Social Psychology, 32, 1-62. https://doi.org/10.1016/s0065-2601(00) 80003-9.

Lederbogen, F., Kirsch, P., Haddad, L., Streit, F., Tost, H., \& Schuch, P., et al. (2011). City living and urban upbringing affect neural social stress processing in humans. Nature, 474(7352), 498-501. https://doi.org/10.1038/nature10190.

Leventhal, T., \& Brooks-Gunn, J. (2000). The neighborhoods they live in: The effects of neighborhood residence on child and adolescent outcomes. Psychological Bulletin, 126(2), 309-337. https://doi. org/10.1037/0033-2909.126.2.309.

Leventhal, T., \& Brooks-Gunn, J. (2003). Children and youth in neighborhood contexts. Current Directions in Psychological Science, 12(1), 27-31. https://doi.org/10.1111/1467-8721.01216.

Leventhal, T., Dupere, V., \& Shuey, E. A. (2016). Children in neighborhoods. In M. H. Bornstein \& T. Leventhal (Eds.), Handbook of child psychology and developmental science (pp. 493-533). Hoboken, N.J.: Wiley.

Leviton, L. C., Snell, E., \& McGinnis, M. (2000). Urban issues in health promotion strategies. American Journal of Public Health, 90(6), 863-866. https://doi.org/10.2105/ajph.90.6.863.

Lilienfeld, S. O. (2003). Comorbidity between and within childhood externalizing and internalizing disorders: Reflections and directions. Journal of Abnormal Child Psychology, 31(3), 285-291. https://doi.org/10.1023/a:1023229529866.

Marcelis, M., Navarro-Mateu, F., Murray, R., Selten, J. P., \& van Os, J. (1998). Urbanization and psychosis: a study of 1942-1978 birth cohorts in The Netherlands. Psychological Medicine, 28(4), 871-879. https://doi.org/10.1017/s0033291798006898.

Miller, P., Votruba-Drzal, E., \& Setodji, C. M. (2013). Family income and early achievement across the urban-rural continuum. Developmental Psychology, 49(8), 1452-1465. https://doi.org/10. 1037/a0030244.

Mizrahi, R. (2016). Social stress and psychosis risk: Common neurochemical substrates? Neuropsychopharmacology, 41(3), 666-674. https://doi.org/10.1038/npp.2015.274.

Mulatu, M. S., \& Schooler, C. (2002). Causal connections between socio-economic status and health: Reciprocal effects and mediating mechanisms. Journal of Health and Social Behavior, 43(1), $22-41$.

Newbury, J., Arseneault, L., Caspi, A., Moffitt, T. E., Odgers, C. L., \& Fisher, H. L. (2016). Why are children in urban neighborhoods at increased risk for psychotic symptoms? Findings from a UK longitudinal cohort study. Schizophrenia Bulletin, 42(6), 1372-1383. https://doi.org/10.1093/schbul/sbw052.

Odgers, C. L., Caspi, A., Russell, M. A., Sampson, R. J., Arseneault, L., \& Moffitt, T. E. (2012). Supportive parenting mediates neighborhood socioeconomic disparities in children's antisocial behavior from ages 5 to 12. Development and Psychopathology, 24(3), 705-721. https://doi.org/10.1017/s0954579412000326.

Pedersen, C. B., \& Mortensen, P. B. (2001). Evidence of a doseresponse relationship between urbanicity during upbringing and schizophrenia risk. Archives of General Psychiatry, 58(11), 1039-1046. https://doi.org/10.1001/archpsyc.58.11.1039.

Peen, J., Schoevers, R. A., Beekman, A. T., \& Dekker, J. (2010). The current status of urban-rural differences in psychiatric disorders. Acta Psychiatrica Scandinavica, 121(2), 84-93. https://doi.org/ 10.1111/j.1600-0447.2009.01438.x. 
Pujol, S., Levain, J. P., Houot, H., Petit, R., Berthillier, M., \& Defrance, J., et al. (2014). Association between ambient noise exposure and school performance of children living in an urban area: A cross-sectional population-based study. Journal of Urban Health-Bulletin of the New York Academy of Medicine, 91(2), 256-271. https://doi.org/10.1007/s11524-013-9843-6.

$\mathrm{R}$ Core Team. (2015). R: A language and environment for statistical computing. Vienna, Austria: R Foundation for Statistical Computing.

Rapee, R. M. (2012). Family factors in the development and management of anxiety disorders. Clinical Child and Family Psychology Review, 15(1), 69-80. https://doi.org/10.1007/s10567011-0106-3.

Ravens-Sieberer, U., Wille, N., Erhart, M., Bettge, S., Wittchen, H.U., \& Rothenberger, A., et al. (2008). Prevalence of mental health problems among children and adolescents in Germany: Results of the BELLA study within the National Health Interview and Examination Survey. European Child \& Adolescent Psychiatry, 17(1), 22-33. https://doi.org/10.1007/s00787-008-1003-2.

Reijneveld, S., Harland, P., Brugman, E., Verhulst, F., \& VerlooveVanhorick, S. (2005). Psychosocial problems among immigrant and non-immigrant children - Ethnicity plays a role in their occurrence and identification. European Child \& Adolescent Psychiatry, 14(3), 145-152. https://doi.org/10.1007/s00787-0050454-y.

Reijneveld, S. A., Veenstra, R., de Winter, A. F., Verhulst, F. C., Ormel, J., \& de Meer, G. (2010). Area deprivation affects behavioral problems of young adolescents in mixed urban and rural areas: The TRAILS study. Journal of Adolescent Health, 46 (2), 189-196. https://doi.org/10.1016/j.jadohealth.2009.06.004.

Rhee, S. H., Lahey, B. B., \& Waldman, I. D. (2015). Comorbidity among dimensions of childhood psychopathology: Converging evidence from behavior genetics. Child Development Perspectives, 9(1), 26-31. https://doi.org/10.1111/cdep.12102.

Rothbaum, F., \& Weisz, J. R. (1994). Parental caregiving and child externalizing behavior in nonclinical samples - A meta-analysis. Psychological Bulletin, 116(1), 55-74. https://doi.org/10.1037/ 0033-2909.116.1.55.

Rudolph, K. E., Stuart, E. A., Glass, T. A., \& Merikangas, K. R. (2014). Neighborhood disadvantage in context: The influence of urbanicity on the association between neighborhood disadvantage and adolescent emotional disorders. Social Psychiatry and Psychiatric Epidemiology, 49(3), 467-475. https://doi.org/10.1007/ s00127-013-0725-8.

Rutter, M. (1981). The city and the child. American Journal of Orthopsychiatry, 51(4), 610-625.

Rutter, M., Cox, A., Tupling, C., Berger, M., \& Yule, W. (1975). Attainment and adjustment in 2 geographical areas. 1. Prevalence of psychiatric-disorder. British Journal of Psychiatry, 126, 493-509. https://doi.org/10.1192/bjp.126.6.493.

Sampson, R. J., Raudenbush, S. W., \& Earls, F. (1997). Neighborhoods and violent crime: A multilevel study of collective efficacy. Science, 277(5328), 918-924. https://doi.org/10.1126/science. 277.5328.918.
Schwab, J. J., Nadeau, S. E., \& Warheit, G. J. (1979). Crowding and mental-health. Pavlovian Journal of Biological Science, 14(4), 226-233.

Sellstrom, E., \& Bremberg, S. (2006). The significance of neighbourhood context to child and adolescent health and well-being: A systematic review of multilevel studies. Scandinavian Journal of Public Health, 34(5), 544-554. https://doi.org/10.1080/ 14034940600551251

Selten, J. P., \& Cantor-Graae, E. (2005). Social defeat: risk factor for schizophrenia? British Journal of Psychiatry, 187, 101-102. https://doi.org/10.1192/bjp.187.2.101.

Statistics Netherlands (2001). Working Population Classifications of Occupations Scheme. Den Haag/Heerlen.

Statistics Netherlands (2015). Statline. www.statline.cbs.nl. Den Haag/ Heerlen.

Statistics Netherlands (2016). Neighborhood Area. Den Haag/Heerlen.

Steinheuser, V., Ackermann, K., Schoenfeld, P., \& Schwabe, L. (2014). Stress and the city: Impact of urban upbringing on the (re) activity of the hypothalamus-pituitary-adrenal axis. Psychosomatic Medicine, 76(9), 678-685. https://doi.org/10.1097/psy. 0000000000000113.

Stone, L. L., Mares, S. H. W., Otten, R., Engels, R., \& Janssens, J. (2016). The co-development of parenting stress and childhood internalizing and externalizing problems. Journal of Psychopathology and Behavioral Assessment, 38(1), 76-86. https://doi. org/10.1007/s10862-015-9500-3.

Lumley, T., Diehr, P., Emerson, S., \& Chen, L. (2002). The importance of the normality assumption in large public health data sets. Annual Review of Public Health, 23(1), 151-169. https://doi.org/ 10.1146/annurev.publhealth.23.100901.140546.

United Nations (2014). World Urbanization Prospects: The 2014 Revision, Highlights (ST/ESA/SER.A/352).

Van Os, J., Driessen, G., Gunther, N., \& Delespaul, P. (2000). Neighbourhood variation in incidence of schizophrenia - Evidence for person-environment interaction. British Journal of Psychiatry, 176, 243-248.

van Os, J., Kenis, G., \& Rutten, B. P. F. (2010). The environment and schizophrenia. Nature, 468(7321), 203-212. https://doi.org/10. 1038/nature09563.

Williams, J. G., Higgins, J. P. T., \& Brayne, C. E. G. (2006). Systematic review of prevalence studies of autism spectrum disorders. Archives of Disease in Childhood, 91(1), 8-15. https://doi. org/10.1136/adc.2004.062083.

Witvliet, M., van Lier, P. A. C., Cuijpers, P., \& Koot, H. M. (2009). Testing links between childhood positive peer relations and externalizing outcomes through a randomized controlled intervention study. Journal of Consulting and Clinical Psychology, 77 (5), 905-915. https://doi.org/10.1037/a0014597.

Votruba-Drzal, E., Miller, P., \& Coley, R. L. (2016). Poverty, urbanicity, and children's development of early academic skills. Child Development Perspectives, 10(1), 3-9. https://doi.org/10.1111/ cdep. 12152.

Zayan, R. (1991). The specificity of social stress. Behavioural Processes, 25(2-3), 81-93.https://doi.org/10.1016/0376-6357(91)90011-n. 